Editorial

\title{
The Myth of Beirut's Resilience: Introduction to the Thematic Issue
}

\author{
Liliane Buccianti-Barakat ${ }^{1}$ and Markus Hesse ${ }^{2, *}$ \\ ${ }^{1}$ Department of Geography, Saint Joseph University, Lebanon \\ 2 Department of Geography and Spatial Planning, University of Luxembourg, Luxembourg \\ * Corresponding author (markus.hesse@uni.lu)
}

Submitted: 27 January 2022 | Published: 23 February 2022

\begin{abstract}
This editorial introduces a thematic issue of Urban Planning on recent developments in Beirut, Lebanon. It emphasises the multiple crises the city has been undergoing for some time, which include an enduring political and economic crisis, the impact of the Covid-19 pandemic, and most recently the devastating impact of the blast that happened in the port of Beirut on 4th August 2020. The editorial outlines the specific challenges resulting from these crises and addresses the concept of resilience, which is taken up by the articles included in this issue.
\end{abstract}

\section{Keywords}

Beirut; Lebanon; resilience; urban development

\section{Issue}

This editorial is part of the issue "Urbanisation, Crisis, and Resilience: The Multiple Dimensions of Urban Transformation in Beirut, Lebanon" edited by Liliane Buccianti-Barakat (Saint Joseph University) and Markus Hesse (University of Luxembourg).

(C) 2022 by the author(s); licensee Cogitatio (Lisbon, Portugal). This editorial is licensed under a Creative Commons Attribution 4.0 International License (CC BY).

\section{Introduction}

Beirut's urban transformation is a subject of significant multi-disciplinary inquiry in the social sciences, urban studies, and political geography (see Arsan, 2018; Bou Akar, 2018; Fawaz, 2017; Fregonese, 2009). We have selected the city as subject of inquiry against the backdrop of the multiple crises Beirut has been undergoing for some time. These include an enduring crisis of the economy and with respect to the political system and institutions, which emerges on the grounds of a civil war lasting more than a decade. As many other countries did in similar ways, Lebanon in general, and Beirut in particular, were hit by the Covid-19 pandemic. The most recent element is the blast in the port of Beirut which happened on 4th August 2020 and left a devastating impact on the city, on its people, and urban life (Fregonese, 2021).

These events created a rather complex assemblage of threats and problems challenging the country and its capital city, and were seen by many as a crystallisation of Lebanon's complicated historical trajectories. However, these episodes do not supplant the rich historical setting both ancient and modern Lebanon represents for urban scholars. Beirut's cultural and geographical liminality, and continuing role as a prominent urban confluence with multi-faceted geographic positionality, imbue it with an especially abundant empirical interest and topical relevance. While there is no doubt about the material and intellectual challenges associated with the current crises, the articles presented here aim not only to provide some novel accounts of urban development in Beirut and Lebanon more generally, but also to inspire politics and policy in the attempt to prepare for recovery. It will be a matter of debate as to how far the concept of resilience can provide some orientation here, and the selection of conceptual and particularly empirical articles included here may be seen as a contribution to this debate.

This thematic issue has evolved from activities under the umbrella of the Urban Commission of the International Geographical Union (UGI-IGU), whose 2020 annual conference was supposed to have taken 
place in Beirut, Lebanon. The same applied to its follow-up conference in 2021, which was devoted topicwise to the multiple challenges of resilience. Both meetings were eventually held as digital conferences, but already offered some close encounter of members of the Commission with a range of researchers from the Middle East-Lebanon and Beirut in particular-and discussed related topics of urban development, policy, and research. Some of the articles included here were already presented on those occasions, others emerged from an international call-for-abstracts. The thematic issue offers a chance to shed some new light on a range of specific Mediterranean and Arab urbanisms-not with respect to those places that already received some attention in recent years (such as Dubai or Doha), but to focus on a place that enjoys both variety and a rich history, while being subject to multiple political crises in recent times as well.

\section{Urban Resilience}

Resilience has had a stunning career over the last 10 to 15 years in the natural and social sciences, and increasingly also in geography and urban studies. By definition, resilience addresses the ability of subjects (individuals, collectives) to absorb short-term incidents and the shocks they exert on societies, cities, and urban regions (Meerow et al., 2016; Townshend et al., 2015). The main premise is that by undertaking precautionary measures, a locale could also recover from unforeseen events, shocks, and crises, and thus regain a state of equilibrium, however defined. The city we are dealing with here as a case in point seems to perfectly demonstrate these variegated challenges.

The huge resonance that the term and concept of resilience received in the last decade(s) was of course spurred on by the three major crises we have witnessed in recent times: the financial crisis in 2008-2009 challenging socio-economic systems also through countermeasures (such as austerity); of course the Covid-19 pandemic as the most visible and enduring crisis widely affecting societies and individuals; and climate change as a persistent, long-term crisis, an epitome of our times. In relation to these three crises separately and in combination, resilience is discussed as a proper response, a strategy for dealing with both the short-term outcomes of disasters, for organising recovery, and for a more substantial transformation. This may also explain why the resilienceframe has meanwhile reached policy mainstream, calling for approaching long-term, fundamental change at urban and regional levels. However, there is good reason to be cautious about both an inflationary and unconsidered use of this concept. If sustainable development has already been quite demanding in terms of effective practice, this applies even more so to resilience.

Our critical reading of resilience includes three aspects: positivism and policy hubris; the machinery of learning and knowing; and subjectification of the problem. First and foremost, concepts of urban and regional resilience deploy a certain sense of positivism, particularly as concerns the root causes of shocks and events that need to be overcome, and also the possible state of equilibrium to which one would seek to return. Additionally, the steering mechanisms of effective resilience would need to be systemic, which has raised some criticism given the implicated causal expectations and linear understanding of policy that are necessarily associated with this concept (Chelleri et al., 2015).

Secondly, the transformation of a conceptual idea into a best-selling product has been driven by a global machinery of learning, knowing, and dissemination. This has raised the suspicion of observers that the equilibrium some resilience actors are searching for is mainly an economic one: creating a tool for the commodification of urban development strategies and benchmarking for bringing the competitive gesture of global urbanisation to the fore (Leitner et al., 2018).

Thirdly, there is a certain degree of subjectification inherent to the concept of resilience. One of the key points in Graefe's (2019) work is to consider the resilient subject as an ideal counterpart to the current neo-liberalised and financialised form of capitalism. This follows the assumption that every form of society needs a subject that suits it. Hence through individual resilience programmes, the subject is rendered fit to endure the uncertainties of present and future. The welfare state was previously the stabilising force against the insecurities and crises of capitalist economies, whereas the appeals for flexibility and measures under the rubric of resilience are articulated in terms of self-motivated actions. This applies even more to cases where the state either failed or remains absent from such traditional role model.

Beirut as a case and place of multiple crises provides a huge challenge for applying the concept of resilience in practice. On the one hand, there are urgent needs for recovery in various regards, involving a wide range of technical and scientific expertise, civil society engagement, and state action-responsibility of the latter seems the most important factor in the trajectory of crises that the country and capital city are undergoing for quite some time. On the other hand, the site can be considered a testing ground par excellence for the very circumstances that may allow for (or not) to recover from shocks and crises. Beirut's experience in approaching recovery and becoming more resilient could thus provide insights, practices, and learning outcomes that render useful for other places as well-if resilience would ever work out there, it would have proven its general value as a guideline for (re-)development.

\section{Beirut: Past and Current Developments}

Beirut is a crossroads in the middle of the eastern Mediterranean basin. This location made the continuity of the port city's history since ancient times. 
Originally called Beroth, City of Wells by the CanaanitePhoenicians, Beirut is an ancient settlement dating back more than 5,000 years. Its history has included so many ebbs and flows; so many destructions and reconstructions along the centuries (Buccianti-Barakat \& Chamussy, 2012). Long considered as a crossroads between Asia, Africa, and Europe, owing to its strategic location, Beirut gained prominence as a Levantine city in the mid-19th century. Since its independence in 1943, the modern state finds itself subject to myriad external pressures which often have destabilising internal effects.

The city's traditional role as a maritime and commercial entrepôt and university city was widened to become a nascent financial centre in 1956 with the introduction of banking secrecy laws. Its subsequent international reputation as a diplomatic hub and tourist resort with various monikers such as the "Switzerland" or "Paris" of the Middle East coincided uneasily with growing geopolitical and migratory pressure flowing from the expulsion of Palestinians by Israel, and it ended abruptly with the outbreak of civil war in 1975. In the 1960s and early 1970s, Beirut became an important cultural centre and a major educational, medical, and commercial hub in the Arab region. However, since the independence of Lebanon in 1943, the city suffers from human-made hazards, i.e., internal and external conflicts and social crises. It underwent several setbacks during the 15-year civil war (1975-1990) and fell victim to several destructions since the 1990s due to the reconstruction of downtown Beirut entrusted to Solidere, a private company, and increasing financialisation of real estate. Periods of post-war reconstruction are the backdrop for new socioeconomic and political dynamics (Fawaz et al., 2018).

Reconstruction after the civil war had only limited success as concerns achieving its ostensible aim of restoring the city's former international status. Alongside the rise of centralised market-led urbanism, laissez-faire urban planning, the embedding of sectarian polarisation, and neglect of basic infrastructure are all factors that raise questions about the model of urban regeneration implemented and arouse new socio-political tensions. Post-modern redevelopment of the inner-city as a site for speculative real-estate investment occurs alongside an intensive, unplanned urbanisation along the coastlines to the north and south, and in stark contrast to the "misery belt" of informal sprawl on the periphery of the city. At the same time, Lebanese people have worked hard after the war to rebuild their shattered homes and lives, and by 2018 Beirut had regained its cultural dynamism and lust for life.

\section{Multiple Crises and the Myth of Beirut's Resilience}

Recent crises not only comprise a long-standing concern about the state's economic failure and clientelist political environment but were exacerbated by the outbreak of Covid-19. As if that would not already be enough of a crisis, on Tuesday, August 4th, 2020, Beirut suffered an extraordinarily strong blast that destroyed its famous commercial port and all the historic districts along the seafront, stretching across a perimeter of several kilometres. The explosion was reportedly felt in Syria, Turkey, and parts of Europe, and was heard in Cyprus, which is more than 240 kilometres away, and it claimed the lives of 220 humans and left more than 6,500 injured (Al-Hajj et al., 2021). The blast was considered one of the most powerful non-nuclear explosions in history according to the United States Geological Survey (2020).

"La catastrophe de trop" (the one disaster too many), as the Lebanese had put it after the double explosion, rendered the country in a fundamental social, health, and economic crisis. The day after the explosion, hundreds of Lebanese volunteers came down to clean, sweep, and distribute water and food to the inhabitants of the stricken areas. At the same time, national associations and NGOs such as ICOMOS Lebanese members, were mobilized on the ground to bring first aid to the residents, followed by international NGOs, the Lebanese diaspora, and many countries around the world helping with medicines, food aid, etc. Once again, the Lebanese took an active part in the reconstruction of the affected neighbourhoods updating the myth of Beirut's resilience.

As the Lebanese writer Nadia Tueni, a francophone poet who is the author of numerous volumes of poetry, wrote: "Elle est mille fois morte, mille fois revécue" (It is a thousand times dead, a thousand times relived). In the novel Stone of Laughter, Hoda Barakat, a Lebanese author, explores the devastated spaces that the civil war opens up in each individual. The clearing has also been associated with the political and psychological amnesia that followed the civil war. Instead of reconciling their differences, the fighting factions and religious sects have chosen not to come to terms with their belligerent past, but to switch from military to tacit documentary form. Paradoxically, the amnesia of Beirut's post war physical reconstruction has played an important role in providing historical continuity between the city's defining myths - the myth of self-consumption and the myth of self-renewal.

According to popular folk culture and history alike, Beirut was propelled into history by a moral judgement, passed long ago, that the city deserves destruction. The 15 years of civil war was just another that endowed Beirut with seductive appeal and notoriety. Beirut's self-consumption, the foundational problem of Lebanon, presents a necessary condition for the cyclical myth to be realized. The second defining myth relates that Beirut will be destroyed but it will rise from the ashes. Popular songs and poetry to this effect reassured citizens in their makeshift shelters that the city would be rebuilt. Even the warlords who were overseeing fulfilment of the myth of self-consumption always insisted that the phoenix would eventually rise again.

The myth of self-destruction feeds the myth of resilience. But a historical survey of this cycle quickly reveals that most of the calamities in the history of Beirut 
were natural, not man-made (earthquakes, tsunamis, etc.). An important matter is time: Until now, the transition from destruction to re-construction has rarely been the responsibility of the same generation. Today, the Lebanese crisis results from a system put in place at the end of the civil war. And the warlords are running the country now. For the Palestinian filmmaker, director, and producer Mai Masri, Beirut is a city that refuses to die. For her, this crumbling city with a tortured past is brimming with culture that continues to inspire artists and tourists. The element of the unexpected, even chaos, leaves significant space for creative expression.

\section{The Articles in This Thematic Issue}

The authors of the articles presented in this thematic issue have chosen different topical matters for discussing the challenge of resilience in the case of Beirut and the multiple crises of the capital city and country. Their subjects include a conceptual reflection of urbanisation of Beirut, a critical discussion of heritage conservation practice, informal urbanisms and their sustainable design, issues of place identity and public space, urban restructuring and densification, or neighbourhood-oriented planning. Accordingly, methods and approaches are varied, from qualitative inquiry, theoretical reflection, and secondary sources' assessment to GIS-applications and agent-based micro simulations. By initiating and presenting this selection of articles, we follow the commitment of the UGI-IGU in general, and its Urban Commission in particular, to promote the production, exchange, and dissemination of geographical knowledge across different parts of the world and to bring the various research communities in conversation with each other. While we do not expect that academic knowledge can be easily "transferred" to practice, the authors of these articles are certainly motivated as well by the need to seek strategies, instruments, and tactics that may help Beirut and Lebanon to recover from their multiple crises.

\section{Acknowledgments}

We are particularly grateful to the colleagues who contributed to the sessions at the meetings of the Urban Commission of the UGI-IGU, and to those who participated in this thematic issue of Urban Planning. Funding was thankfully received from the University of Luxembourg's Department of Geography and Spatial Planning.

\section{Conflict of Interests}

The authors declare no conflict of interests.

\section{References}

Al-Hajj, S., Dhaini, H. R., Mondello, S., Kaafarani, H., Kobeissy, F., \& DePalma, R. G. (2021). Beirut ammonium nitrate blast: Analysis, review, and recommendations. Frontiers in Public Health, 9, Article 657996. https://doi.org/10.3389/fpubh.2021.657996

Arsan, A. (2018). Lebanon. A country in fragments. Hurst \& Co.

Bou Akar, H. (2018). For the war yet to come. Stanford University Press.

Buccianti-Barakat, L., \& Chamussy, H. (2012). Le Liban: Géographie d'un pays paradoxal [Lebanon: Geography of a paradoxical country]. Belin.

Chelleri, L., Waters, J., Olazabal, M., \& Minucci, G. (2015). Resilience trade-offs: Addressing multiple scales and temporal aspects of urban resilience. Environment and Urbanization, 27(1), 181-198.

Fawaz, M. (2017). Exceptions and the actually existing practice of planning: Beirut (Lebanon) as case study. Urban Studies, 54(8), 1938-1955.

Fawaz, M., Krijnen, M., \& El Samad, D. (2018). A property framework for understanding gentrification: Ownership patterns and the transformations of Mar Mikhael, Beirut. City, 22(3), 358-374.

Fregonese, S. (2009). The urbicide of Beirut? Geopolitics and the built environment in the Lebanese civil war (1975-1976). Political Geography, 28(5), 309-318.

Fregonese, S. (2021). Shockwaves: Atmospheres beyond the conflict city/ordinary city divide. Conflict and Society, 7(1), 26-41.

Graefe, S. (2019). Resilienz im Krisenkapitalismus. Wider das Lob der Anpassungsfähigkeit [Resilience in crisis capitalism. Against the praise of adaptability]. Transcript.

Leitner, H., Sheppard, E., Webber, S., \& Colven, E. (2018). Globalizing urban resilience. Urban Geography, 39(8), 1276-1284.

Meerow, S., Newell, J. P., \& Stults, M. (2016). Defining urban resilience: A review. Landscape and Urban Planning, 147, 38-49.

Townshend, I., Awosoga, O., Kulig, J., \& Fan, H. (2015). Social cohesion and resilience across communities that have experienced a disaster. Natural Hazards, 76(2), 913-938.

United States Geological Survey. (2020). M 3.3 explosion-1 km ENE of Beirut, Lebanon. https:// earthquake.usgs.gov/earthquakes/eventpage/ us6000b9bx/executive 


\section{COGITATIO}

\section{About the Authors}

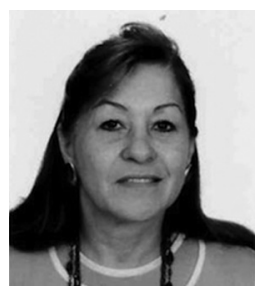

Liliane Buccianti-Barakat is professor of urban studies, tourism, and cultural heritage at the Saint Joseph University of Beirut with an academic background in urban geography. Her research interests focus on urban and landscape policies in Lebanon and the MENA region. She is currently vice-president of ICOMOS Lebanese National Committee who got involved with several NGO's after the explosion of the port on August 4th, 2020, for the rescue of the urban heritage of the affected neighbourhoods. She is a member of the Urban Commission of the International Geographical Union (UGI-IGU). She is currently responsible for the university degree in religious tourism in Lebanon.

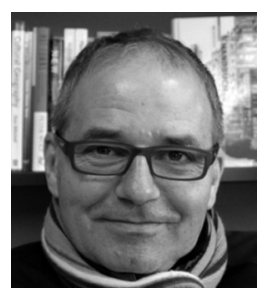

Markus Hesse is professor of urban studies at the University of Luxembourg, with an academic background in geography and spatial planning. His research interests focus on the intersections of urban development, economic geography, and metropolitan governance. Also, some emphasis is placed on the science-policy interface in urban planning and governance. He currently serves as a vice-president of the Urban Commission of the International Geographical Union (UGI-IGU). 